\begin{tabular}{c} 
Volume and Issues Obtainable at Center for Sustainability Research and Consultancy \\
Journal of Business and Social Review in Emerging Economies \\
ISSN: 2519-089X \& ISSN (E): 2519-0326 \\
Volume 7: Issue 3 September 2021 \\
CSRᄃ \\
Journal homepage: www.publishing.globalcsrc.org/jbsee \\
\hline
\end{tabular}

\title{
Cotton Yield and Climate Change Adaptation in Pakistan: Application of Multinomial Endogenous Switching Regression Model
}

\author{
Aisha Siddiqua, IPFP fellow at University of Education, Lahore, Pakistan \\ Aftab Anwar, Department of Economics, University of Education, Lahore, Pakistan \\ *Muhammad Masood Anwar, Women University of Azad Jammu Kashmir, Bagh, Pakistan \\ Jamshaid ur Rehman, Government College University Lahore, Pakistan
}

*Corresponding author's email: smasood_ajk@yahoo.com

\begin{tabular}{l}
\hline ARTICLEDETAILS \\
\hline History \\
Revised format: Aug 2021 \\
Available Online: Sep 2021 \\
\hline Keywords \\
Adaptation, \\
Climate Change, \\
Cotton farming, \\
Multinomial Endogenous \\
Switching, \\
Treatment effect. \\
\hline
\end{tabular}

JEL Classification

M11, M12

\section{ABSTRACT}

Purpose: Cotton is the backbone of Pakistan economy, as country is the 4th largest producer of cotton in the world. Despite this importance there is steep decline in cotton production over time due to climate change. The need to evaluate the potential of adaptation in improving cotton yield has necessitated this study. Design/Methodology/Approach: This study is based on the farm household survey of four cotton producing districts, two from each Punjab and Sindh that were purposively selected from heat stress regions of Pakistan. Data were analyzed through multinomial endogenous switching regression model and treatment effect framework.

Findings: Farm management practices were evaluated for their significance in reducing adverse impacts of climatic extremes on cotton yield. Adaptation in the combination of first three strategies observed to be the most successful strategies in increasing yield.

Implications/Originality/Value: For effective adaptation access to credit and extension, education, farming experience, and sources of information revealed to be important predictors

(C2021The authors, under a Creative Commons Attribution-

Recommended citation: Siddiqua, A., Anwar, A., Anwar, M. M. and Rehman, J. (2021). Cotton Yield and Climate Change Adaptation in Pakistan: Application of Multinomial Endogenous Switching Regression Model. Journal of Business and Social Review in Emerging Economies, 7(3), 491-502.

\section{Introduction}

It is revealing fact that climate change has emerged as one of the core issues of the current time and that it is affecting a significant portion of the population worldwide by disturbing food production, natural ecosystem, health and water supply, in major dimensions (Hassan, et al. 2005). Climate change has severe impacts on the natural systems, such as agriculture due to increase in the intensity and frequency of climatic extremes, warmer days and nights, and 
frequent heat waves and heavy precipitation (IPCC 2007).

Adverse impacts of Climate change could be reduced by mitigating and adapting to it, however, mitigation is a long run process and efforts to mitigate the carbon emission and related greenhouse gases could not bring its fruits without effective adaptation (Parry, et al. 1998). Sectors such as agriculture are more prone to the direct impacts of changing climatic conditions and could be best prepared to face its adverse impacts by adapting to the change. Adaptation in agriculture is utmost importance to face the daunting challenge of providing food and other inevitabilities to the growing world population that is expected to grow to nine billion by 2050 (Clements et al. 2011).

Adaptation involves a two stage process; first perceiving the change in climatic conditions and then decision to adapt on the basis of their perceptions. Furthermore, adaptation influenced by the local climatic and agro-ecological conditions, farmer's adaptive capacity, their socioeconomic characteristics, information on climate change adaptation, and institutional arrangements (Maddison 2007; Gorest et al., 2015). Changes in farm management practices such as change in the time of sowing, irrigation practices, fertilizer application and new seeds varieties (flood and drought tolerant etc), prove as relatively expensive adaptation strategies and successful in moderating the impact of adverse climatic events (Burke and Lobell 2010; Robert et al., 2016).

Cotton is not only a major cash and fiber crop of Pakistan, rather country is also ranked fifth in the world in its production (World Cotton Production, 2017-18). Even though area under cotton production has increased, its production keeps on declining in Pakistan due to unfavorable climatic conditions and lack of water at the main stages of crop development along with pest attack (GOP, 2020). Cotton is sensitive to the water availability particularly at the flowering and boll formation stages (Zonta et al., 2017). In Pakistan erratic patterns of rainfall and wide reaching climate heating has proven to have more depressing impact on cotton yield (Abbas 2020; Rehman et al., 2019). In the history of Pakistan, the decade of the 2000s was the warmest period and 2014 to 2016 were the hottest years (Ahmad et al., 2016). A warming trend has been signified during the past three decades, but predominantly in 2000-2016 (Ahmad et al., 2016). Cotton production has declined by $33.9 \%$ in Pakistan; from 10.7 million bales in 2017 to 5.951 million bales in 2019 in Punjab province (Pakistan Cotton Ginners Association).

In this study we analyzed the impact of variations in climatic conditions on crop development stages of cotton. Multinomial Endogenous Switching regression model applied to study the impact of temperature and precipitation normal and their deviations on yield. A disaggregated analysis performed to study the potential of different crop specific adaptation strategies in enhancing cotton yield. We have also studied the factors determining cotton farmer's decision to adapt these strategies in isolation or in combination.

\section{Material and Methods}

This study is carried out in the cotton producing districts of Bahawalpur, Vehari, Sanghar, and Mirpurkhas. Temperature in cotton belt of Pakistan stay in the range of $40-45^{\circ} \mathrm{C}$ (Figure 1) that is much higher than the optimal temperature range of $28.5^{\circ} \mathrm{C}$. Due to inadequate rainfall (150 to $750 \mathrm{~mm}$ ) cotton belt in Pakistan mostly depends on irrigation (Figure 2) via the Indus River and its tributaries, water from which has declined due to the melting of glaciers on Himalayan and decline in snowfall (Rees and Collins, 2004; IPCC, 2007). Cotton takes the third biggest share of fresh water in Pakistan after rice and sugarcane (WWF 2005). Average cotton production in Sindh is $850 \mathrm{~kg} / \mathrm{ha}$ and in Punjab $692 \mathrm{~kg} / \mathrm{ha}$ that is lower than the average world yield.

Due to non-availability of water farmers have shifted to less water consuming crops, as cotton in 
Pakistan is a small farmers' crop, with around $86 \%$ of farms under cotton cultivation are of less tha five hectares. Cotton remains an important source income of these small holders. Heat stress has become the major reason behind decline in the per capita yield of cotton in Pakistan (Raza 2009, Malik \& Ahsan 2016). Other factors contributing in the decline of cotton production are cotton leaf curl virus disease $(\mathrm{CLCuV})$, decline in water for irrigation, erratic rainfall, high input prices (fertilizer, seed, pesticide, insecticide, etc.), pest attacks, and shortage of good quality seed (Malik \& Ahsan, 2016).

Fig 1: Temperature of Cotton region in Pakistan

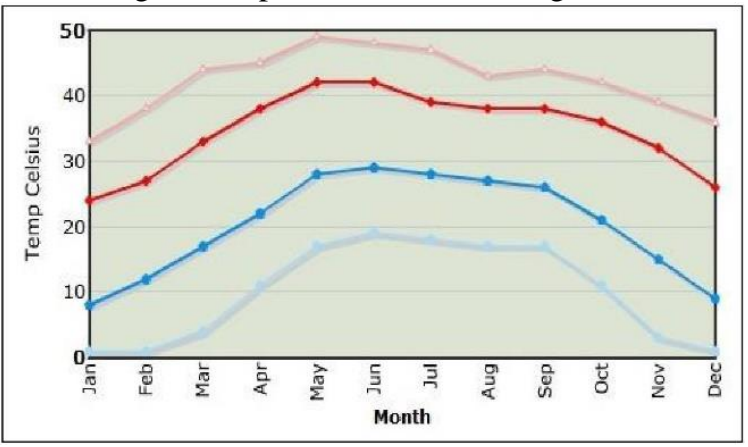

Sources: Malik \& Ahsan (2016)
Figure 2: Precipitation in Cotton region of Pakistan

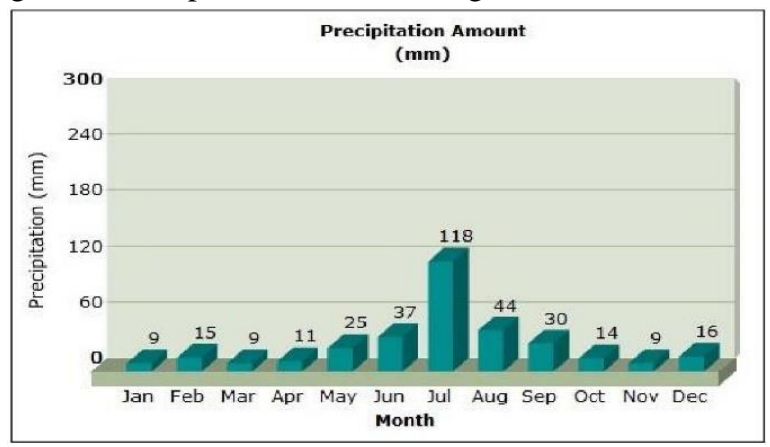

Sources: Malik \& Ahsan (2016)

Historical climate data (1960-2018) of temperature and precipitation were collected from Pakistan Meteorological Department (PMD). While estimates of mean temperature and rainfall for each stage of crop development were calculated by the author. Data for socioeconomic characteristics of farm households, farm characteristics, and climate change awareness and adaptation were collected through household survey.

\section{Multinomial Endogenous Switching (MES) regression model}

To achieve the above-mentioned goals, Multinomial Endogenous Switching (MES) regression model is applied. Model is adapted on the grounds that there is presence of endogeneity stimulated from the influence of unobservable characteristics on both adaptation decision and yield. MES regression model take care of the sample selection bias present in the farmer's decision making. When farmer's select adaptation strategies their choices are voluntary. They self-select on the basis of their individual unobservable characteristics (such as those who received extension service or other farm trainings are more skilled, motivated and capable to adapt). Those who have adapted may have systematically different characteristics from those who did not adapt. Hence, it is important to control for the endogeneity stimulated from the influence of these unobservable.

Our model control for this selection bias by estimating the simultaneous equation model with endogenous switching. In this model, farmers switch among regimes of yield (outcome equation) as per their status of adaptation (selection equation). Let $A^{*}$ be the latent variable that captures the expected benefits from adaptation (an increase in yield) and $Y_{i}$ is outcome variable of interest (cotton yield), then we can specify our model as;

$A_{i}{ }^{*}=b Z_{i}+v_{i}>0$

$Y_{0 i}=f_{i 1}\left(A_{i}=0\right)=\beta X_{i 1}+u_{i 1}$

$Y_{1 i}=f_{i 2}\left(A_{i}=1\right)=\gamma X_{i 2}+u_{i 2}$

$Y_{n i}=f_{i n}\left(A_{i}=n\right)=\gamma X_{i n}+u_{i n}$

Where, $A_{i}=1$ if $A_{i 1} *>\max _{k \neq 1}\left(A_{i k}^{*}\right)$ or $A_{i}=2$ if $A_{i 2} *>\max _{k \neq 2}\left(A_{i k}^{*}\right) \ldots . . A_{n}=1$ if $A_{\text {in }} *$ 
$>\max _{k \neq n}\left(A_{i k}^{*}\right)$

Farmers are facing $\mathrm{n}$ regimes (mutually exclusive strategies); first regime represents reference category of non-adaptation (eq 2a), $Z_{i}$ and $X_{i}$ are vectors of variables for adaptation (eq 1) and yield equations ( 2 a to $2 \mathrm{n}$ ) respectively. Variables in $Z_{i}$ includes education, household size, farm size, farm experience, access to credit and extension service by government, information on climate change from radio, newspaper, TV, family members, neighbors and department of agriculture. While, $X_{i}$ has climate variables of temperature and precipitation normal for each growth stage, short run climate related shock $^{1}$, regional dummies ${ }^{2}$, and factors of production (seed, fertilizer, labor, tractor and irrigation).

To calculate the consistent estimates of the coefficients of outcome equation, we followed Bourguignon, et al. (2007) and estimated the following selection bias-corrected output equations:

$y_{1 i}=\beta X_{1 i}+\sigma_{1}\left[r h o_{1} m_{i 1}+\sum r h o_{j} m_{i j} \frac{P_{i j}}{\left(P_{i j}-1\right)}\right]+\epsilon_{1 i}$ if $A_{i}=1$

$y_{2 i}=\beta X_{2 i}+\sigma_{2}\left[r h o_{2} m_{i 2}+\sum r h o_{j} m_{i j} \frac{P_{i j}}{\left(P_{i j}-1\right)}\right]+\epsilon_{2 i}$ if $A_{i}=2$

$y_{n i}=\beta X_{n i}+\sigma_{n}\left[r h o_{n} m_{i n}+\sum r h o_{j} m_{i j} \frac{P_{i j}}{\left(P_{i j}-1\right)}\right]+\epsilon_{n i}$ if $A_{i}=n$

Where $P_{i j}=\frac{e^{b_{J} z_{i}}}{1+\sum e^{b_{J} z_{i}}}$. is the probability that household $i$ choose strategy $j$ for $\mathrm{J}=1, \ldots \ldots, \mathrm{j}, r h o_{i}$ is correlation between error terms of adaptation equation and production functions and takes values between -1 and 1 , while $m_{i j}$ are the selection bias correction terms for each adaptation strategy. Probability of selecting an adaptation strategy is a discrete choice and is conditioned on the independent variables $\mathrm{X}$ (socio-economic conditions; agro-ecological setting of farmers and institutions factors) $)^{3}$.

\section{Treatment Effect Framework}

We applied the treatment effect framework to understand the role of adaptation in enhancing crop yield, by comparing the expected yield of farm households who have adapted, with those who did not adapted. This framework help us in identifying the most successful strategies to enhance the output of cotton in the face of climate adversaries. By following Bourguignon, et al. (2007) and Di Falco, et al. (2013), expected yield of the adapters for strategy $\mathrm{j}=1 \ldots \mathrm{n}$, is calculated as;

$\mathrm{E}\left(y_{2 i} \mid A_{i}=2\right)=\beta_{2} X_{i}+\sigma_{2}\left[r h o_{2} m_{i 2}+\sum r h o_{j} m_{i j} \frac{P_{i j}}{\left(P_{i j}-1\right)}\right]$ for $\mathrm{j} \neq 2 \ldots \mathrm{n}$

$\mathrm{E}\left(y_{3 i} \mid A_{i}=3\right)=\beta_{3} X_{i}+\sigma_{3}\left[r h o_{3} m_{i 3}+\sum r h o_{j} m_{i j} \frac{P_{i j}}{\left(P_{i j}-1\right)}\right]$ for $\mathrm{j} \neq 3 \ldots \mathrm{n}$

$\mathrm{E}\left(y_{n i} \mid A_{i}=\mathrm{n}\right)=\beta_{n} X_{i}+\sigma_{n}\left[r h o_{n} m_{i n}+\sum r h o_{j} m_{i j} \frac{P_{i j}}{\left(P_{i j}-1\right)}\right]$ for $\mathrm{j}=1 \ldots . \mathrm{n}-1(2.3 \mathrm{n})$

While, the counterfactual of adaptation for those have adapted (if they did not adapt), is calculate

\footnotetext{
${ }^{1}$ Calculated as deviations of current climatic variables at different growth stages from their respective climatic normal

${ }^{2}$ Cotton produce either in Punjab or in Sindh, hence we introduce the regional dummy to capture the impact of location.

${ }^{3}$ Marginal effectsor the likelihood of the occurrence of a particular choice made by farmers with respect to a unit change in explanatory variable is calculated as; $\frac{\partial \operatorname{Pr}(Y=J)}{\partial x_{i}}=\operatorname{Pr}(Y=J / x)\left[\beta_{j i}-\sum \beta_{j i} \times \operatorname{Pr}(Y=J / x)\right]$
} 
as;

$\mathrm{E}\left(y_{1 i} \mid A_{i}=2\right)=\beta_{1} X_{i}+\sigma_{1}\left[r h o_{1} m_{i 2}+r h o_{2} m_{i 1} \frac{P_{i 1}}{\left(P_{i 1}-1\right)}+\sum r h o_{j} m_{i j} \frac{P_{i j}}{\left(P_{i j}-1\right)}\right]$ for $\mathrm{j}=3 \ldots \mathrm{n}$
$\mathrm{E}\left(y_{1 i} \mid A_{i}=3\right)=\beta_{1} X_{i}+\sigma_{1}\left[\begin{array}{c}r h o_{1} m_{i 3}+r h o_{2} m_{i 1} \frac{P_{i 1}}{\left(P_{i 1}-1\right)}+r h o_{3} m_{i 2} \frac{P_{i 2}}{\left(P_{i 2}-1\right)}+ \\ \sum r h o_{j} m_{i j} \frac{P_{i j}}{\left(P_{i j}-1\right)}\end{array}\right]$ for $\mathrm{j}=4 \ldots \mathrm{n}$.

$\mathrm{E}\left(y_{1 i} \mid A_{i}=n\right)=\beta_{1} X_{i}+\sigma_{1}\left[r h o_{1} m_{\text {in }}+\sum r h o_{j} m_{i, j-1} \frac{P_{i, j-1}}{\left(P_{i, j-1}-1\right)}\right]$ for $\mathrm{j}=2 \ldots \mathrm{n}$

Finally, we calculated the treatment effect of the treated (impact of adaptation on adaptors) by subtracting Equation 2.3ac from Equation 2.3a and so on-Equation 2.3nc from Equation 2.3n.

\section{Adaptation Strategies}

In this paper we constructed mutually exclusive groups of crop specific adaptation strategies; change in time of sowing, input intensification, and change in the application of irrigation by irrigating more or less, and adoption of new crop varieties. For a more comprehensive and meaningful analysis, we grouped strategies into four different categories: change in the time of sowing, inputs intensification, change in irrigation, and varietal change ${ }^{4}$. Various groups of adaptations and their combinations, constructed mutually exclusively are described in Table 1.

Table 1: Description of the crop specific adaptation strategies cotton farmer's adapted in isolation or in combination

\begin{tabular}{|c|c|}
\hline Strategy & Description \\
\hline $\mathrm{C}_{0}$ : No adaptation & 1 if the farm household did not adapt any strategy, 0 otherwise \\
\hline $\mathbf{C}_{1}$ : Change in time of sowing only & $\begin{array}{l}1 \text { if the farm household changed the timings of sowing by } \\
\text { sowing early or late as an adaptation strategy, } 0 \text { otherwise }\end{array}$ \\
\hline $\mathbf{C}_{2}$ : Input intensification only & $\begin{array}{l}1 \text { if the farm household intensified use of seed rate and fertilizer } \\
\text { as adaptation strategy, } 0 \text { otherwise }\end{array}$ \\
\hline $\mathbf{C}_{3}$ : Change in time of irrigation only & $\begin{array}{l}1 \text { if the farm households increased or decreased irrigation as } \\
\text { adaptation strategy, } 0 \text { otherwise }\end{array}$ \\
\hline $\mathbf{C}_{\mathbf{4}}$ : Varietal Change only & $\begin{array}{l}1 \text { if farm households use drought tolerant, flood tolerant, short } \\
\text { cycle or longer cycle variety as adaptation strategy; } 0 \text { otherwise }\end{array}$ \\
\hline $\begin{array}{l}\mathbf{C}_{12}: \text { Change in time of sowing and Input } \\
\text { intensification }\end{array}$ & $\begin{array}{l}1 \text { if the farm household adapted by changing the timings of } \\
\text { sowing and by intensifying inputs, } 0 \text { otherwise }\end{array}$ \\
\hline $\begin{array}{l}\mathbf{C}_{13} \text { : Change in time of sowing and irrigation } \\
\text { change }\end{array}$ & $\begin{array}{l}1 \text { if the farm household adapted by che } \\
\text { sowing and by changing irrigation, } 0 \text { other }\end{array}$ \\
\hline $\begin{array}{l}\mathbf{C}_{\mathbf{1 4}} \text { : Change in time of sowing and varietal } \\
\text { change }\end{array}$ & $\begin{array}{l}1 \text { if the farm household adapted by changing the timings of } \\
\text { sowing and by adapting varietal change, } 0 \text { otherwise }\end{array}$ \\
\hline $\mathbf{C}_{23}$ : Input intensification and Irrigation change & $\begin{array}{l}1 \text { if the farm household adapted by intensifying inputs of sowing } \\
\text { and by changing irrigation, } 0 \text { otherwise }\end{array}$ \\
\hline $\mathbf{C}_{24}$ : Input intensification and varietal change & $\begin{array}{l}1 \text { if the farm household adapted by intensifying inputs and by } \\
\text { adapting varietal change, } 0 \text { otherwise }\end{array}$ \\
\hline $\mathrm{C}_{34}$ : Irrigation change and Varietal change & $\begin{array}{l}1 \text { if the farm household adapted by changing irrigation and by } \\
\text { adapting varietal changing, } 0 \text { otherwise }\end{array}$ \\
\hline $\begin{array}{l}\mathbf{C}_{123}: \text { Change in time of sowing, input } \\
\text { intensification, and irrigation change }\end{array}$ & $\begin{array}{l}1 \text { if the farm household adapted by changing the timings of } \\
\text { sowing, by intensifying inputs and by changing irrigation, } 0 \\
\text { otherwise }\end{array}$ \\
\hline $\begin{array}{l}\mathbf{C}_{124} \text { : Change in time of sowing, input } \\
\text { intensification, and varietal change }\end{array}$ & $\begin{array}{l}1 \text { if the farm household adapted by changing the timings of } \\
\text { sowing, by intensifying inputs and by varietal change, } 0 \\
\text { otherwise }\end{array}$ \\
\hline $\mathbf{C}_{134}$ : Change in time of sowing, irrigation & 1 if the farm household adapted by changing the timings \\
\hline
\end{tabular}

${ }^{4}$ We grouped early and late sowing as "change in time of sowing"; use of more seed and fertilizer are grouped as "inputs intensification"; change in irrigation either by increasing or decreasing irrigation is combined under the label of "change in irrigation" and choices of adapting short cycle, longer cycle, flood tolerant or drought tolerant varieties as "Varietal change". 


\begin{tabular}{|l|l|} 
change, and varietal change & $\begin{array}{l}\text { sowing, by changing irrigation and by varietal change, } 0 \\
\text { otherwise }\end{array}$ \\
\hline $\begin{array}{l}\mathbf{C}_{\mathbf{2 3 4}} \text { : Input intensification, irrigation change, } \\
\text { and varietal change }\end{array}$ & $\begin{array}{l}1 \text { if the farm household adapted by intensifying inputs, by } \\
\text { changing irrigation and by varietal change, } 0 \text { otherwise }\end{array}$ \\
\hline $\begin{array}{l}\mathbf{C}_{\mathbf{1 2 3 4}} \text { : Change in time of sowing, Input } \\
\text { intensification, irrigation change and varietal } \\
\text { change }\end{array}$ & 1 if the farm household adapted all strategies, 0 otherwise \\
\hline
\end{tabular}

Sources: Author's Compilation

Application of fertilizer is considered to be essential to grow more food on the same cropland (Waha, et al. 2013; Amdu, et al. 2013). However, use of fertilizer is dependent on the nutrients needs of the crop and can produce good yield only when applied at the right time and in balance with other inputs. While, irrigation is not only an essential element for the crop production, rather it is another important strategy to mitigate the adverse impacts of climate change (Hassan, et al. 2008) especially for the farmers of drought-prone areas (Amdu, et al. 2013). Farmers can adjust the interval between irrigation episodes as per the changes in the weather. Increase in warming should be offset by reducing the interval between irrigation (Tack, et al. 2017). However, effectiveness of irrigation to increase yield is only possible with proper timing and adequate amount of irrigation (Rai et al., 2017).

Adaptation of drought and flood tolerant varieties can substantially reduce the adverse impact of these catastrophes on the agriculture sector (FAO 2011). To counter the reduction in output due to shortening of season or lengthening of the growing cycle, shorter and longer cycle varieties have been introduced.

\section{Results and Discussion}

In this section we discuss and analyze the impact of adaptation strategies on yield of farmer when they adapted in isolation or a portfolio of strategies ${ }^{5}$, determinants of adaptation and role of adaptation in enhancing expected yield of those who have adapted vs those who did not.

\section{Impact of Climatic factors on Cotton Yield in the presence of adaptation}

To estimate MES model, selection instruments of education, household and farm size, farm experience, access to credit, extension services, irrigation and sources of information on climate have been used in the model ${ }^{6}$.

Cotton grows more slowly in cool atmosphere, and its development is strongly influenced by temperature. Optimal temperature range for cotton growth is 20 to $30^{\circ} \mathrm{C}$ (Reddy, et al. 1991). We observed a significant non-linear impact of increase in temperature at all stages of crop development with a significant U-shaped impact of temperature on output at the first, second, and fourth stage of production, while a linear impact of increase in temperature and precipitation at the third stage of production (Table 1). Among inputs of production, fertilizer establish a significant positive impact on the yield (Table 2).A U-shaped impact of high temperature at the first stage (germination) could be attributed to the impact of an excessively high and above average mean temperature in the presence of adaptation.

For last twenty years temperature in Pakistan at the germination stage stay at around $36^{\circ} \mathrm{C}$, which is much higher than the optimal range of $28-30^{\circ} \mathrm{C}$ (Krzyzanowski, et al. 2011). However, with adaptation in portfolio (irrigation change and new crop varieties) adverse impacts of this increase in temperature has been reversed (Table 2). At the vegetation stage U-shaped relationship

\footnotetext{
${ }^{5}$ selmlog command in STATA 13 is used to run Multinomial Endogenous Switching Regression Model.

${ }^{6}$ These variables have a direct influence on the decision of farmers to adapt to climate change and indirectly through the channel of adaptation on the yield.
} 
between temperature and cotton output could be ascribed to the role played by the combination of strategies $\mathrm{C} 12$ and $\mathrm{C} 24$ (Table 2). Vegetative phase requires moderate temperature and humidity for the formation of stem and broadening of leaves, an increase in temperature at this stage increases node and leaf appearance and extreme temperature will result into shedding of leaves and pest attack (Raza and Ahmad 2015).

Similarly, at the fourth stage of production a significant U-shaped relationship observed between temperature and cotton output when farmers are adapting strategies in combination of C12 and C24 (Table 2). While, at third stage of production temperature has significantly positive and linear impact on output, which could be explained by the fact that mean temperature at this stage for last twenty years in Pakistan is $31^{\circ} \mathrm{C}$ which is not much higher than the optimal range of 28$30^{\circ} \mathrm{C}$ to cause an adverse impact. Furthermore, farmers are also adapting to the climate change by introducing change in irrigation and by introducing new crop varieties that could also battle the negative impacts of a slight increase in temperature beyond the optimal range. (Table 2).

Table2: Estimates of the Multinomial Endogenous Switching Regression Model

\begin{tabular}{|c|c|c|c|c|c|c|c|c|c|}
\hline Variables & $\mathbf{C}_{0}$ & $\mathbf{C}_{2}$ & $\mathrm{C}_{12}$ & $\mathrm{C}_{23}$ & $\mathrm{C}_{24}$ & $\mathrm{C}_{123}$ & $\mathrm{C}_{124}$ & $\mathbf{C}_{234}$ & $\mathrm{C}_{1234}$ \\
\hline Stage1Precp & 6.37 & 11.45 & 168.24 & 5.38 & 93.33 & 16.5 & 0.44 & -9.53 & -2.7 \\
\hline Stage1PrecipSqr & -0.18 & 0.24 & 0.08 & -0.49 & -4.94 & -0.54 & 0.22 & 0.2 & 0.08 \\
\hline Stage2Precp & -7.47 & 0.71 & -25.69 & -5.51 & 248.71 & -12.52 & 5.92 & 2.72 & -0.94 \\
\hline Stage2PrecpSqr & 0.05 & -0.02 & 0.13 & 0.04 & -1.59 & 0.08 & -0.03 & -0.01 & 0 \\
\hline Stage3Precip & 7.82 & 7.56 & 101.36 & 4.19 & -35.24 & 5.02 & -2.49 & 0.73 & 2.3 \\
\hline Stage3PrecpSqr & -0.06 & -0.03 & -0.92 & -0.04 & 0.34 & -0.03 & -0.01 & -0.01 & -0.01 \\
\hline Stage4Precp & 4.99 & -13.3 & -35.9 & 6.59 & 1.12 & -1.67 & -17.07 & 0.74 & -1.02 \\
\hline Stage4PrecipSqr & -0.1 & 0.35 & 0.5 & -0.27 & -0.63 & -0.01 & 0.47 & 0.04 & 0.04 \\
\hline Stage1 temp & -66.5 & -40.7 & 61.54 & 153.97 & $-12.03 * * *$ & 249.68 & 184.02 & 369.61 & -183.69 \\
\hline Stage1TempSqr & 8.35 & 6.38 & -5.94 & -12.89 & $18.44 * *$ & -3.22 & -2.93 & -5.19 & 2.33 \\
\hline Stage2Temp & 88.14 & 77.48 & $-361.3 * * *$ & -62.4 & $-88.06 * *$ & 15.64 & 416.06 & 200.12 & 179.48 \\
\hline Stage2TempSqr & -13.5 & -8.2 & $45.61 * *$ & 1.61 & $93.93 * * *$ & 0.11 & -4.71 & -2.11 & -2.27 \\
\hline Stage3Temp & -46.3 & -52.7 & 174.66 & -87.27 & $606.73 * * *$ & -118.9 & -406.3 & -34.83 & -51.32 \\
\hline Stage3TempSqr & 6.24 & 5.39 & -23.91 & 10.36 & -68.54 & 1.45 & 5.09 & 4.57 & 0.61 \\
\hline Stage4Temp & 58.44 & 56.29 & $-36.65 * * *$ & 245.14 & $-569.8 * * *$ & 28.29 & 66.53 & 64.68 & 16.57 \\
\hline Stage4TempSqr & -0.94 & -8.2 & $6.08 * * *$ & -4.13 & $95.35 * * *$ & -0.59 & -1.2 & -0.87 & -0.26 \\
\hline Stage1PrecpDev & 2.21 & 14.67 & 173.25 & -9.18 & -57.52 & 0.48 & 6.09 & -3.57 & -0.08 \\
\hline Stage2PrecpDev & 0.05 & 0.01 & -0.13 & -0.17 & -1.69 & 0.04 & 0.02 & -0.05 & $0.06 *$ \\
\hline Stage3PrecpDev & -0.16 & 0.24 & 13.5 & -0.05 & -1.45 & -0.36 & -0.39 & -0.01 & 0.02 \\
\hline Stage4PrecpDev & 1.2 & -0.25 & 20.99 & -1.41 & 3.43 & -2 & -1.3 & 0.8 & -0.31 \\
\hline Stage1TempDev & -14.9 & 3.78 & 282.59 & 2.94 & 157.98 & -20.72 & -12.82 & -15.94 & -16.55 \\
\hline Stage2TempDev & 23.91 & 15.67 & -337.35 & 20.19 & -1538.8 & 44.02 & 22.31 & 24.22 & $25.36^{*}$ \\
\hline Stage3TempDev & -2.01 & -29.7 & -3.55 & -29.41 & 91.95 & -32.04 & -8.08 & -14.52 & -14.87 \\
\hline Stage4TempDev & 3.96 & 2.97 & 454.74 & 0.37 & 104.89 & 1.07 & -12.89 & 4.16 & 0.33 \\
\hline RegionalDummy & -0.6 & -4.47 & -17.94 & 2.76 & -737.89 & -7.28 & -20.6 & -2.28 & -3.81 \\
\hline Tractor & 0.43 & 2.66 & 0.66 & -1.69 & -2.39 & 0.1 & -0.69 & -1.11 & 0.69 \\
\hline Seed & -0.02 & -0.92 & -0.84 & -0.61 & 0.65 & -0.5 & -0.22 & 0.23 & -0.39 \\
\hline Labor & -0.09 & -0.12 & 0.26 & 0.2 & 0.03 & 0.14 & 0.14 & 0.08 & 0.11 \\
\hline Fertilizer & $1.79 *$ & 2.97 & 0.54 & 2.27 & 0.79 & 0.58 & 1.96 & $2.84 * *$ & $2.05 * * *$ \\
\hline Irrigation & -1.69 & -1.97 & 2.32 & -4.87 & -6.67 & 1.1 & -8.69 & 0.67 & -0.67 \\
\hline Constant & 783.2 & -259 & $718.55 * * *$ & -954.2 & $3959.8 * * *$ & -329.5 & -464.4 & -619.2 & 857.58 \\
\hline
\end{tabular}


We also observed a significantly positive impact of weather shock on yield due to deviation of temperature from its long run mean of $35^{\circ} \mathrm{C}$ by $2^{\circ} \mathrm{C}$ at the vegetation stage (Table 2). It proves a beneficial shock as long-term mean temperature $\left(35^{\circ} \mathrm{C}\right)$ at this stage is already much higher than the optimal range of $20^{\circ} \mathrm{C}$ to $30^{\circ} \mathrm{C}$. Besides, farmer's adaptation of all crop specific adaptation strategies give them strength to reverse the negative impacts of climatic shocks ${ }^{7}$.

\section{Evaluating the role of Adaptation to Climate Change in Enhancing Cotton Yield}

In this section, we use the treatment effect framework to assess the success of adaptation strategies in enhancing cotton productivity ${ }^{8}$. Table 3 reported results for expected gains in yield against the alternate of no adaptation.Expected gain from adaptation are highest (31\%) for cotton when farmers adapt the combination C123 (Table 3). This gain reduces to $20 \%$ when farmers adapted new crop varieties in place of changes in the time of sowing that is a decline of $11 \%$ points. Expected yield will also increase to $14 \%$ and $16 \%$ respectively when farmers are adapting to the combinations of $\mathrm{C} 124$ and $\mathrm{C} 1234$ (Table 3$)^{9}$.

Table 3: Expected increase in cotton yield from adaptation to climate change

\begin{tabular}{|c|c|c|c|}
\hline Strategy/ Crop & Frequency & Treatment Effect & $\begin{array}{l}\text { Percentage } \\
\text { Gain }\end{array}$ \\
\hline (C1) Change in time of sowing only & 5 & & \\
\hline (C2) Input intensification only & 86 & $0.38 * * *(0.76)$ & 19 \\
\hline (C3) Change in time of irrigation only & 45 & & \\
\hline (C4) Varietal Change only & 18 & & \\
\hline (C12) Change in time of sowing and Input intensification & 52 & $11.43(1.79)$ & \\
\hline (C13) Change in time of sowing and irrigation change & 8 & & \\
\hline (C14) Change in time of sowing and varietal change & 8 & & \\
\hline (C23)Input intensification and Irrigation change & 128 & $0.29(0.58)$ & \\
\hline (C24) Input intensification and varietal change & 84 & & \\
\hline (C34) Irrigation change and Varietal change & 14 & & \\
\hline $\begin{array}{l}\text { (C123) Change in time of sowing, input intensification and } \\
\text { irrigation change }\end{array}$ & 148 & $7.01 * * *(0.59)$ & 31 \\
\hline $\begin{array}{l}\text { (C124) Change in time of sowing, input intensification, } \\
\text { and varietal change }\end{array}$ & 76 & $3.36 * * *(0.64)$ & 14 \\
\hline $\begin{array}{l}\text { (C134) Change in time of sowing, irrigation change, and } \\
\text { varietal change }\end{array}$ & 8 & & \\
\hline $\begin{array}{l}\text { (C234) Input intensification, irrigation change and } \\
\text { varietal change }\end{array}$ & 133 & $4.61 * * *(0.31)$ & 20 \\
\hline $\begin{array}{l}\text { (C1234) Change in time of sowing, Input intensification, } \\
\text { irrigation change and varietal change }\end{array}$ & 302 & $3.85 * * *(0.23)$ & 16 \\
\hline
\end{tabular}

Source: Author's Compilation

The results, however, lead us to conclude that strategies of change in time of sowing and irrigation are beneficial strategies for cotton growers when they are combined with inputs intensification, and it is the most successful portfolio for cotton growers. Although we do not have significant influence of the strategy of varietal change, preceding results cannot exclude it as an important adaptation strategy. More research is required to understand the potential of all crop specific strategies when they are adapting in isolation.

\section{Determinants of adaptation}

\footnotetext{
${ }^{7}$ We have incorporated regional dummy of Sindh to capture the influence of CC on cotton yield in Sindh province. We performed estimation by incorporating both dummies of Punjab and Sindh together and only one at a time. We don't find significant dummy in any case, except when dummy for Sindh incorporated alone.

${ }^{8}$ Estimation of the model requires a large number of observation, hence results for only those cases are reported where there is enough observation to regress the model.

${ }^{9}$ There were not enough observations for C1, C3, C4, C13, C14, C24, C34, and C134 to performthe treatmentanalyses.
} 
We have highlighted the importance of adaptation in our preceding discussion, hence it accentuatesthe need to analyze those characteristics that incentive and provoke farmers for adaptation. Through multivariate regression model we examined the influence of different socioeconomic, farm specific and institutional characteristics on farmer's decision to adapt. Adaptation is endogenous and discrete choice variable, and composed of fifteen mutually exclusive adaptation categories ${ }^{10}$. Results of the MNL model (in terms of marginal effects Table 4) indicates that households' adaptive capacity, farm size, credit, extension services, and various sources of information on climate change influence farm household's capability to adapt to climate change.

Table 4: Marginal Effects of Multinomial Logit model of Cotton farmer's Adaptation to Climate Change

\begin{tabular}{|l|c|c|c|c|c|c|c|}
\hline Variables & $\mathbf{C}_{\mathbf{2}}$ & $\mathbf{C}_{\mathbf{3}}$ & $\mathbf{C}_{\mathbf{4}}$ & $\mathbf{C}_{\mathbf{1 2}}$ & $\mathbf{C}_{\mathbf{1 3}}$ & $\mathbf{C}_{\mathbf{1 4}}$ & $\mathbf{C}_{\mathbf{2 3}}$ \\
\hline Education & 0.092 & $*-0.02$ & $\mathbf{1 . 2 4} * * *$ & 0.05 & 0.02 & $\mathbf{0 . 1 2} * *$ & $\mathbf{0 . 4 7} * *$ \\
\hline HH Size & 0.097 & $\mathbf{1 . 8 6} * *$ & $0.26^{*}$ & 0.26 & $\mathbf{0 . 2 5} *$ & -2.73 & 0.02 \\
\hline Farm Size & 0.021 & $\mathbf{- 1 . 5 7}$ & $0.05^{*}$ & $\mathbf{0 . 1 5}$ & 0.26 & 0.47 & 0.004 \\
\hline Farm Experience & -0.027 & $\mathbf{0 . 0 7 8} * *$ & $\mathbf{0 . 6 2} * * *$ & 2.66 & $\mathbf{0 2 8} *$ & 0.51 & 0.58 \\
\hline Credit & $\mathbf{0 . 3 1} * *$ & 2.667 & $\mathbf{0 . 2 3} * *$ & $\mathbf{1 . 0 5} * *$ & 0.02 & $\mathbf{0 . 0 3} *$ & $\mathbf{0 . 0 9}$ \\
\hline Extension & -0.74 & -1.27 & $\mathbf{0 . 5 4} *$ & $\mathbf{0 . 1 9} *$ & $\mathbf{0 . 4 8} *$ & 0.07 & -0.03 \\
\hline TV & 0.76 & 0.28 & $\mathbf{0 . 7 4}$ & 2.45 & $\mathbf{0 . 0 4} *$ & 0.02 & 0.01 \\
\hline Radio & $\mathbf{- 0 . 4 2}$ & -1.16 & 0.01 & 0.01 & 0.02 & 0.21 & -0.01 \\
\hline Newspaper & 0.01 & 4.31 & 1.58 & 0 & 0.01 & 0.24 & -0.02 \\
\hline Family & 0.22 & $\mathbf{1 . 9 2} * *$ & 2.27 & $\mathbf{0 . 6 8} *$ & $\mathbf{0 . 2 2} *$ & $\mathbf{0 . 0 5} * *$ & $\mathbf{0 . 0 3 2}$ \\
\hline $\begin{array}{l}\text { Depof } \\
\text { Agriculture }\end{array}$ & -1.53 & -1.64 & $\mathbf{0 . 4 7 *}$ & $\mathbf{0 . 0 2} *$ & $\mathbf{0 . 4 7} *$ & $\mathbf{0 . 0 8 * *}$ & 0.04 \\
\hline $\begin{array}{l}\text { Traditional } \\
\text { Knowledge }\end{array}$ & -0.07 & $\mathbf{1 . 4 4} * *$ & 0.93 & 0 & $\mathbf{0 . 2 2} * *$ & $\mathbf{0 . 2 6} *$ & 0.45 \\
\hline
\end{tabular}

Table 4: Continue

\begin{tabular}{|c|c|c|c|c|c|c|c|}
\hline Variables & $\mathrm{C}_{24}$ & $\mathrm{C}_{34}$ & $C_{123}$ & $C_{124}$ & $C_{134}$ & $\mathrm{C}_{234}$ & $\mathrm{C}_{1234}$ \\
\hline Education & 0.015* & 0.023* & 0.007 & 0.04* & 0.23 & $0.06 *$ & 0.003* \\
\hline HH Size & 0.04 & 0.48 & 0.25 & 0 & 0.007 & 0.14 & 0.07* \\
\hline Farm Size & $0.12 *$ & $0.14 *$ & 0.058* & $0.36^{*}$ & 0.001 & 0 & 0.04 \\
\hline Farm Experience & $0.004 *$ & -1.56 & $0.02 * *$ & $0.52 * *$ & $0.04 *$ & 0.58 & $0.08 *$ \\
\hline Credit & 0.06* & 0 & -0.06 & 0.01 & 0 & 0.02 & 0.001* \\
\hline Extension & -0.36 & -0.01 & -0.05 & 0.004 & 0.021* & 0 & $0.10 * *$ \\
\hline TV & 0.54 & $0.047 *$ & $0.037 * *$ & 0.08* & 0.06** & 0.06* & -0.02 \\
\hline Radio & $\begin{array}{l}-0.01 \\
\end{array}$ & 0.23 & 0.012* & 0.06 & $0.07 *$ & 0 & 0.06 \\
\hline Newspaper & 0.07 & 0.17 & 0.05 & 0.14 & $0.001 * *$ & -0.01 & -0.02 \\
\hline Family & $0.036 * * *$ & 0.58 & -0.01 & -0.01 & 0.004 & 0.01 & -0.07 \\
\hline Dep of Agriculture & 0.58 & 0.94 & 0.02 & $0.06 * *$ & $0.09 *$ & -0.022 & -0.05 \\
\hline $\begin{array}{l}\text { Traditional } \\
\text { Knowledge }\end{array}$ & 0.14 & 0.12 & $0.029 *$ & 0.45 & 0.007 & -0.03 & 0.01 \\
\hline
\end{tabular}

Source: Author's Compilation

Our results highlighted the importance of large farm size in farmer's decision to introduce changes in irrigation practice either in isolation or in a portfolio with crop varieties (Table 4). Stringer et al. (2020) and Di Falco, et al. (2011) have also established that the adaptation interventions are more easy and effective for large scale farmers, as they have more access to capital and resources, which increases their ability to invest in new technologies. Besides, farmers with large landholdings have better access to cheap credit, they enjoy economies of scale, which enable them to face the uncertainty involved in the adoption of new varieties and technologies (O'Brien, et al. 2000). We also observed an important role of farming experience in

${ }^{10}$ Non adaptation is taken as base strategy and so its results are not reported. 
adaptation decision making. Experienced farmers are normally well informed of the changing climatic conditions as they have experienced climatic events in past. They can also make decision with more certainty as they have adopted new techniques over time to cope with changing climatic conditions (Gbetibouo 2009, Uddin, et al. 2014).

Farmer's access to credit to adapt to climate change, is observed to be of significant importance in the area of study. Farmers with sufficient access to credit are more likely to adapt the strategies of input intensification and new crop varieties in isolation or in combination with other (Table 4). Studies by Di Falco, et al. (2011), Gorestet al. (2015) and Abidet al. (2015) also identified a significant role of credit in adaptation to climate change for Pakistan. Role of credit for farming communities of Pakistan also highlighted by the fact that lack of access to finances is a major constraint (reported by 53 percent) farmers confronted with in order to adapt to climate change.

Furthermore we have also witnessed the importance of extension services in adaptation related to farm management practices and new technologies. Farmers with access to extension are more likely to spread the risk of climate change by taking up a portfolio of adaptation strategies (Table 4). Previously Bryan, et al. (2009); Di Falco, et al. (2013); Abidet al., (2015) have also examined the role of extension services in improving farmers ability to adapt to climate change. We have also identified a prominent contribution of climate change related information in farmer's decision to adapt in line with the studies of Di Falco, et al. (2013) and Bryan, et al. (2013). Our results have featured the importance of media (TV, radio, newspaper), social circle (family and neighbors), traditional knowledge, and department of agriculture in enriching the farmer's awareness of climate change, which lead to adaptation.

\section{Conclusion}

The study highlighted the adverse impacts of extreme temperature and lack of water for irrigation on cotton production in Pakistan. There is a high possibility that unfavorable climatic conditions will further impact cotton farmers in future, which require urgent actions to adapt to these changes. To this end, this study was designed to investigate the effectiveness of crop specific adaptation strategies in the cotton belt of Pakistan, based on the farm household survey in Punjab and Sindh. Results of the Multinomial endogenous switching regression model authenticate the importance of adaptation in reducing the adverse impacts of climate extremes of temperature and precipitation on cotton yield at different crop development stages. Furthermore, evaluation of the effectiveness of these strategies through treatment effect framework also revealed the role of adaptation in combination to increase yield while farmers are facing temperature extremes and erratic precipitation. To improve cotton farmer's capability for adaptation, access to credit and extension services, education and sources of information on climate change should be the priority interventions by policy makers. Such actions would be beneficial for sustainable cotton farming in the face of climate change impact in the region.

\section{References}

Abbas, S. (2020). Climate change and cotton production: an empirical investigation of Pakistan. Environmental Science and Pollution Research, 27, 29580-29588.

Abid, M., Scheffran, J., Schneider, U. A., \&Ashfaq, M. J. E. S. D. (2015). Farmers' perceptions of and adaptation strategies to climate change and their determinants: the case of Punjab province, Pakistan. Earth System Dynamics, 6(1), 225-243.

Ahmad, S.; Nadeem, M.; Abbas, G.; Fatima, Z.; Zeb Khan, R.J.; Ahmed, M.; Ahmad, A.; Rasul, G.; Azam Khan, M. Quantification of the effects of climate warming and crop management on sugarcane phenology. Clim. Res. 2016, 71, 47-61.

Amdu B, Ayehu A, Deressa A (2013) Farmers' perception and adaptive capacity to climate 
change and variability in the upper catchment of Blue Nile, Ethiopia. The African Technology Policy Studies Network (ATPS), Nairobi, Kenya

Bourguignon, Franc, ois, Martin Fournier, and Marc Gurgand. 2007. "Selection Bias Corrections Based on the Multinomial Logit Model: Monte Carlo Comparisons." Journal of Economic Surveys 21 (1): 174-205. Bryan, E., Deressa, T. T., Gbetibouo, G. A., and Ringler, C. (2009). Adaptation to climate change in Ethiopia and South Africa: options and constraints. Environmental science and policy, 12(4), 413-426.

Burke, M., and Lobell, D. (2010). Food security and adaptation to climate change: What do we know?. In Climate Change and Food Security (pp. 133-153). Springer Netherlands.

Clements, R., Haggar, J., Quezada, A., Torres J. (2011). Technologies for climate change adaptation-agriculture sector. In X. Zhu (Ed.). Practical action Technology challenging poverty.GEF/UNEP TNA Guidebook Series UNEP Risø Centre on Energy, Climate and Sustainable Development Ris $\emptyset$ DTU National Laboratory for Sustainable Energy, Roskilde Denmark. http://tech-action.org/ Technologies for climate change adaptationagriculture sector.

Di Falco, S., \& Veronesi, M. (2013). How can African agriculture adapt to climate change? A counterfactual analysis from Ethiopia. Land Economics, 89(4), 743-766.

Gbetibouo, G. A. (2009). Understanding farmers' perceptions and adaptations to climate change and variability: The case of the Limpopo Basin, South Africa (Vol. 849). Intl Food Policy Res Inst.

Gorest, A., G. Ben and D. Ali. 2015. Crop productivity and adaptation to climate change. Centre for climate change economics and policy working paper no. 214. Grantham Res. Inst. Clim. Change Environ. Working Pap. No. 189.

Hassan, R., Scholes, R., \& Ash, N. (2005). Ecosystems and human well-being: current state and trends: findings of the Condition and Trends Working Group. eds.

Hassan, R., and Nhemachena, C. (2008). Determinants of African farmers' strategies for adapting to climate change: Multinomial choice analysis. African Journal of Agricultural and Resource Economics, 2(1), 83-104.

IPCC. 2007. Fourth Assessment Report (AR4), Climate Change 2007, Intergovernmental Panel on Climate Change. Cambridge: Cambridge University Press

Krzyzanowski, F. C., and Delouche, J. C. (2011). Germination of cotton seed in relation to temperature. RevistaBrasileira de Sementes, 33(3), 543-548.

Maddison, D. J. (2007). The perception of and adaptation to climate change in Africa. World Bank Policy Research Working Paper, (4308).

Malik, T. H., \& Ahsan, M. Z. (2016). Review of the cotton market in Pakistan and its future prospects. $O C L, 23(6)$, D606.

Parry, M. L., and Carter, T. R. (1989). An assessment of the effects of climatic changes on agriculture. Climatic Change, 15(1-2), 95-116.

Rai, R. K., Singh, V. P., \&Upadhyay, A. (2017). Planning and evaluation of irrigation projects: methods and implementation. Academic press.

Raza SH. 2009. Cotton production in Pakistan. A grower's view. Presentation (ppt.) at the 68th ICAC Plenary Meeting. International Cotton Advisory Committee (ICAC). United States of America.

Rees G, Collins DN. 2004. An assessment of the Potential Impacts of Deglaciation, Snow and Glacier Aspects of Water Resources Management in the Himalayas (SAGAR MATHA). Centre for Ecology and Hydrology, Oxfordshire, UK.

Reddy, V.R., D.N. Baker, and H.F. Hodges. 1991. Temperature effect on cotton canopy growth, photosynthesis, and respiration. Agron. J. 83:669-704

Robert, M., Thomas, A., \&Bergez, J. E. (2016). Processes of adaptation in farm decision-making models. A review. Agronomy for sustainable development, 36(4), 1-15.

Stringer, L. C., Fraser, E. D., Harris, D., Lyon, C., Pereira, L., Ward, C. F., \&Simelton, E. (2020). Adaptation and development pathways for different types of 
farmers. Environmental Science \& Policy, 104, 174-189.

Tack, J., Barkley, A., \& Hendricks, N. (2017). Irrigation offsets wheat yield reductions from warming temperatures. Environmental Research Letters, 12(11), 114027.

The government of Pakistan (GOP) (2012). Pakistan Economic Survey, http://www.finance.gov.pk/survey/chapter_20/02_Agriculture.pdf

Waha, K., Müller, C., Bondeau, A., Dietrich, J. P., Kurukulasuriya, P., Heinke, J., and LotzeCampen, H. (2013). Adaptation to climate change through the choice of cropping system and sowing date in sub-Saharan Africa. Global Environmental Change, 23(1), 130-143.

Zonta, J. H., Brandao, Z. N., Rodrigues, J. I. D. S., \&Sofiatti, V. (2017). COTTON RESPONSE TO WATER DEFICITS AT DIFFERENT GROWTH STAGES 1. RevistaCaatinga, 30, 980-990. 